\title{
PERANCANGAN PROTOTYPE JEMURAN OTOMATIS MENGGUNAKAN SENSOR AIR DAN SENSOR LDR BERBASIS MIKROKONTROLER ARDUINO UNO DENGAN METODE FLC
}

\author{
Nur Apipah Harahap \\ STMIK Budi Darma, Medan, Indonesia \\ Jalan Sisingamangaraja No. 338, Simp Limun, Medan, Indonesia
}

\begin{abstract}
Abstrak
Indonesia adalah Negara tropis yang memiliki dua musim yaitu musim hujan dan musim panas . pada saat musim hujan tiba, mayoritas orang merasa cemas ketika sedang menjemur pakaiannya. Rasa cemas tersebut akan bertambah pada saat menjemur pakaian namun sedang berada diluar rumah, dan dirumah sedang tidak ada orang. Dari kejadian itu orang jadi enggan menjemur pakaian ditempat terbuka, karna khawatir jemurannya basah terkena air hujan ketika ditinggal oleh pemilikinya saat beraktivitas diluar rumah.Metode FLC (Fuzzy Logic Controller) merupakan sebuah metode yang dalam operasi hanya mengenal 0 dan 1, on atau off tidak operasi yang samar-samar, tidak ada abu-abu yang ada hanya hitam atau putih. Dan ini adalah sesuatu yang logis. Dari gambaran masalah yang terjadi, penulis menemukan ide untuk membuat alat penarik jemuran yang bisa bekerja secara otomatis, meskipun sudah ada beberapa orang yang telah membuat dengan mekanisme yang sama menggunakan Arduino Mega 2560, dengan sebuah kondisi gelap dan terang saja, maka disini penulis ingin mencoba memperbaharui cara mekanisme dari kerja alat tersebut dengan Menggunakan Arduino Uno, dan mencari kondisi disaat panas terik akan tetapi hujan, maka metode ini menjawab apa yang harus dilakukan dengan menerapan logika Fuzzy Logic Controller di dalam mikrokontroller arduino uno tersebut.
\end{abstract}

Kata Kunci : Jemuran, Fuzzy Logic Controller, Arduino Uno.

\section{Abstract}

Indonesia is a tropical country that has two seasons, rainy and summer. when the rainy season arrives, the majority of people feel anxious when drying their clothes. The anxiety will increase when drying clothes but is outside the house, and at home, there are no people. From this incident, people were reluctant to hang clothes in the open, because they were afraid that their clothes would get wet when they were left by their owners while doing activities outside the house. FLC (Fuzzy Logic Controller) method is a method that only knows 0 and 1 in operation. The vague operation, there is no gray only black or white. And this is something logical. From the description of the problems that occur, the authors find the idea to make clothesline pullers that can work automatically, even though there are already some people who have made the same mechanism using Arduino Mega 2560, with just a dark and bright condition, here the author wants to try to renew the way the mechanism of the device works by using Arduino Uno, and look for conditions when the heat is hot but rain, then this method answers what must be done by applying the logic of Fuzzy Logic Controller inside the Arduino Uno microcontroller.

Keywords: Clothesline, Fuzzy Logic Controller, Arduino Uno.

\section{PENDAHULUAN}

Jemuran pakaian adalah sebuah tempat untuk mengeringkan pakaian dimana letak jemuran berada di luar rumah dan di buat di ruang terbuka agar pakaian itu terkena sinar matahari secara langsung agar pakaian kering secara cepat. Indonesia adalah Negara tropis yang memiliki dua musim yaitu musim hujan dan musim panas. Pada saat musim hujan tiba, mayoritas orang merasa cemas ketika sedang menjemur pakaiannya. Rasa cemas tersebut akan bertambah pada saat menjemur pakaian namun sedang berada diluar rumah, dan dirumah sedang tidak ada orang, selain permasalahan tersebut biasanya hujanpun terjadi saat panas maka oleh sebab itu penulis mencoba menyesaikan sebuah masalah tersebut menggunakan sebuah mikrokontroler arduino uno untuk mengubah sistem jemuran yang manual menjadi otomatis dimana jemuran akan mengeluarkan jemuran tersebut ketika sensor $L D R$ terkena sebuah paparan sinar matahari dan akan menarik jemuran kedalam ketika sensor air hujan terkena tetesan air hujan dimana semua input tersebut di kontrol oleh mikrokontoler arduino uno menggunakan metode fuzzy dimana metode tersebut adalah solusi untuk memecahkan masalah ketidak pastian atau samar seperti halnya panas namun hujan.

Metode Fuzzy Logic ini diformulasikan dalam rangka mencari nilai tengah antara bilangan Aristoteles 0 dan 1. Logika biner 0 atau 1 dasar berfikirnya adalah dari filsuf Aristoteles yang mengajarkan hukum berfikir bahwa sesuatunya mesti tergolong benar atau salah. Logika biner hanya mengenal on atau off, hidup atau mati, gelap atau terang, benar atau salah.Tidak ada yang samar-samar, tidak ada abu-abu yang ada hanya hitam atau putih. Jika tidak 1 maka 0, jika tidak gelap berarti terang dan ini adalah sesuatu yang logis. Dari gambaran masalah yang terjadi, penulis menemukan ide untuk membuat alat penarik jemuran yang bisa bekerja secara otomatis, meskipun sudah ada beberapa orang yang telah membuat dengan mekanisme yang sama menggunakan Arduino 
Mega 2560, dengan sebuah kondisi gelap dan terang saja, maka disini penulis ingin mencoba memperbaharui cara mekanisme dari kerja alat tersebut dengan Menggunakan Arduino Uno, dan mencari kondisi disaat panas terik akan tetapi hujan, maka metode ini menjawab apa yang harus dilakukan. Alat tersebut dijalankan menggunakan Mikrokontroler Arduino uno ditambah dengan sensor air dan sensor LDR (Light Dependent Resistor) [5].

Jemuran otomatis ini akan dibangun menggunakan mikrokontroler arduino uno sebagai pengontrol sebuah sensor yang akan menghidupkan motor dc yang menarik jemuran masuk dan keluar, sensor itu menggunakan sebuah sensor $L D R$ dan sensor air dimana ketika sensor $L D R$ terkena paparan sinar matahari maka moter dc akan bekerja untuk mengeluarkan jemuran ke tempat panas dan ketika sensor hujan terkena air hujan maka motor dc akan bekerja untuk menarik jemuran diluar kedalam agar tidak terkena hujan. Selain itu posisi panas akan tetapi hujan inilah yang menjadi masalah, oleh sebab itu metode fuzzy yang akan menentukan kesamaran pada saat kondisi panas hujan tersebut dimana jemuran akan tetap di luar terkena hujan atau menarik ke dalam agar tidak terkena hujan. Sesuai dengan kebutuhan maka ketika panas hujan motor $d c$ akan menarik jemuran ke dalam agar tidak terkena hujan.

\section{TEORITIS}

\subsection{Sistem Pendukung Keputusan}

Jemuran adalah suatu media yang digunakan seseorang ketika orang tersebut akan mengeringkan sebuah pakaian maupun benda atau alat lainnya, biasanya jemuran banyak digunakan untuk mengeringkan sebuah pakaian yang terletak di luar ruangan yang terkena sinar matahari secara langsung dimana proses pengeringan pakaian tersebut dilakukan secara manual dari luar ruangan yang terkena paparan sinar matahari.

\subsection{Mikrokontroler Arduino}

Mikrokontroler Arduino adalah kit elektronik atau papan rangkaian elektronik open source yang didalamnya terdapat komponen utama, yaitu sebuah chip mikrokontroler dengan jenis $A V R$ dari perusahaan Atmel. Mikrokontroler itu sendiri terdiri dari atau IC (integrated circuit) yang bisa di program menggunakan komputer. Tujuan menanamkan program pada mikrokontroler adalah agar rangkaian elektonik dapat membaca input, memproses input tersebut kemudian menghasilkan output sesuai yang diinginkan. Jadi mikrokontroler bertugas sebagai 'otak' yang mengendalikan input, proses dan output sebuah rangkaian elektronik.

Secara umum, arduino terdiri dari dua bagian, yaitu:

1. Hardware berupa papan input/output (I/O) yang open source.

2. Software arduino yang juga open source, meliputi software arduino IDE untuk menulis program dan driver untuk koneksi dengan computer

Arduino uno adalah papan mikrokontroler berbasis ATmega328 yang memiliki 14 pin digital input-output (di mana 6 pin dapat digunakan sebagai output PWM),6 input analog, clock speed $16 \mathrm{MHz}$, koneksi USB, jack listrik, header ICSP ,dan tombol reset. Board ini menggunakan daya yang terhubung kekomputer dengan kabel $U S B$ atau daya eksternal dengan adapter AC-DC atau baterai.

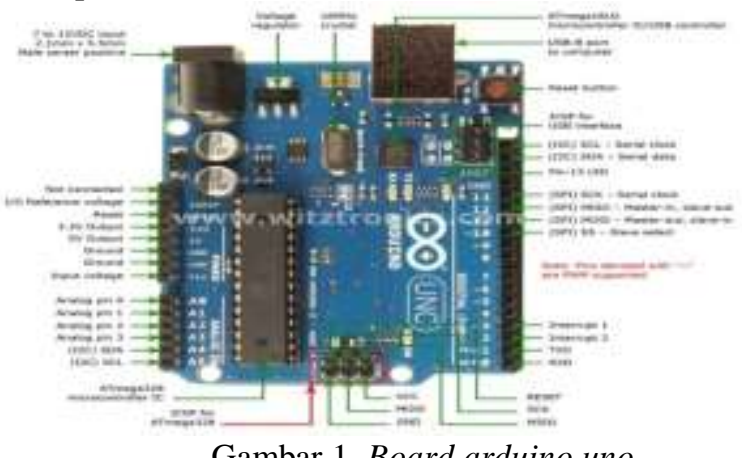

Gambar 1. Board arduino uno

Sumber : http://www.witztronics.com , 2016

Arduino dapat diaktifkan melalui koneksi USB atau dengan catu daya eksternal (non-USB) dapat berasal dari adapter AC-ke-DC atau baterai.

\subsection{Fuzzy Logic}

Fuzzy logic adalah sebuah metodologi berhitung dengan variabel kata-kata (linguistic variabel), sebagai pengganti berhitung dengan bilangan. Kata-kata yang digunakan dalam fuzzy logic memang tidak sepresisi bilangan, namun kata-kata jauh lebih dekat dengan intuisi manusia. Manusia bisa langsung merasakan nilai dari variabel kata-kata 
yang sudah dipakainya sehari-hari. Demikianlah, fuzzy logic memberi ruang dan bahkan mengeksploitasi toleransi terhadap ketidakpresisian.

\subsection{Light Dependent Resistor}

Light Dependent Resistor atau disingkat dengan LDR adalah jenis Resistor yang nilai hambatan atau nilai resistansinya tergantung pada intensitas cahaya yang diterimanya. Nilai hambatan LDR akan menurun pada saat cahaya terang dan nilai hambatannya akan menjadi tinggi jika dalam kondisi gelap. Dengan kata lain, fungsi LDR (Light Dependent Resistor) adalah untuk menghantarkan arus listrik jika menerima sejumlah intensitas cahaya (Kondisi Terang) dan menghambat arus listrik dalam kondisi gelap.Naik turunnya nilai hambatan akan sebanding dengan jumlah cahaya yang diterimanya. Pada umumnya, Nilai Hambatan LDR akan mencapai 200 Kilo Ohm $(\mathrm{k} \Omega)$ pada kondisi gelap dan menurun menjadi $500 \mathrm{Ohm}(\Omega)$ pada Kondisi Cahaya Terang. LDR (Light Dependent Resistor) yang merupakan Komponen Elektronika peka cahaya ini sering digunakan atau diaplikasikan dalam Rangkaian Elektronika sebagai sensor pada Lampu Penerang Jalan, Lampu Kamar Tidur, Rangkaian Anti Maling, Shutter Kamera, Alarm dan lain sebagainya.

\section{ANALISA DAN PEMBAHASAN}

Kebutuhan akan efektivitas dan efisiensi sangat diutamakan dalam berbagai bidang. Hal tersebut telah mendorong manusia untuk berkreasi dan berinovasi dalam bidang teknologi untuk menciptakan sebuah alat yang lebih efektif dan efisien. Misalnya eketif dan efisien dari kebutuhan rumah tangga seperti mesin cuci yang bisa mencuci sendiri, selain dari itu inovasi akan hal barupun dibutuhkan seperti halnya jemuran.

Jemuran pakaian adalah sebuah tempat untuk mengeringkan pakaian dimana letak jemuran berada di luar rumah dan di buat di ruang terbuka agar pakaian itu terkena sinar matahari secara langsung agar pakaian kering secara cepat. Indonesia adalah Negara tropis yang memiliki dua musim yaitu musim hujan dan musim panas. Pada saat musim hujan tiba, mayoritas orang merasa cemas ketika sedang menjemur pakaiannya. Rasa cemas tersebut akan bertambah pada saat menjemur pakaian namun sedang berada diluar rumah, dan dirumah sedang tidak ada orang, selain permasalahan tersebut biasanya hujanpun terjadi saat panas.

Dengan permasalahan diatas penulis mencoba menyesaikan sebuah masalah tersebut menggunakan sebuah mikrokontroler arduino uno untuk mengubah sistem jemuran yang manual menjadi otomatis dimana jemuran akan mengeluarkan jemuran tersebut ketika sensor $L D R$ terkena sebuah paparan sinar matahari dan akan menarik jemuran kedalam ketika sensor air hujan terkena tetesan air hujan dimana semua input tersebut di kontrol oleh mikrokontoler arduino uno menggunakan metode fuzzy dimana metode tersebut adalah solusi untuk memecahkan masalah ketidak pastian atau samar seperti halnya panas namun hujan. Pada perancangan, setiap sensor di letakkan di atas atap rumah agar input yang di dapatkan sempurna terhadap mikrokontroler arduino uno, dan arduino uno sendiri di letakan di dalam rumah di bagian yang tidak tekena air maupun air hujan bersama dengan letak motor dc 1 dan motor de 2 karna bisa mengakibatkan mikrokontroler dan motor de tersebut rusak apabila terkena air atau air hujan.

Dalam pengerjaan Fuzzy Logic Controler terlebih dahulu menentukan fuzzyfikasi seperti dalam penyelesaian berikut:

1. Sensor LDR

Sensor $L D R$ menangkap sinar terang $(280 \Omega)$

$280 \Omega=$ Terang $(0.3)$, Gelap $(0.7)$

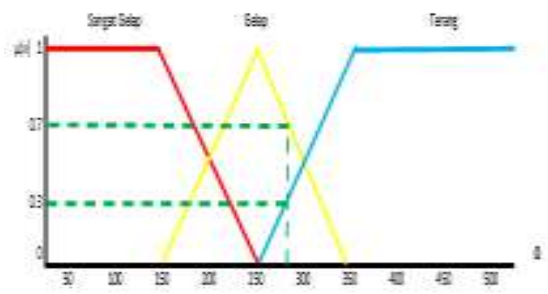

Gambar 2. Kondisi sensor LDR ( input)

2. Sensor Air Hujan

Sensor Air Hujan menangkap tetesan air hujan ( 5 milidetik )

5 milidetik = Basah (0.5), Sangat Basah (0.5) 


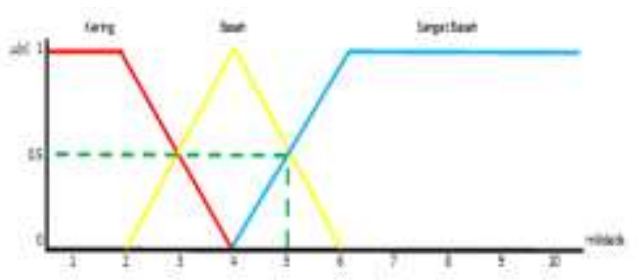

3. Operasi fuzzy dan implikasi:

Gambar 3. Kondisi sensor Air Hujan ( input)

R1: If sensor ldr gelap and sensor air basah then dc on

$\operatorname{Max}(0,7 ; 0.5)=0.7$

R2 : If sensor ldr terang and sensor air kering then dc off $\operatorname{Min}(0.3 ; 0.5)=0.3$

4. Agreasi dan Defuzzifikasi

Persamaan garis ON melalui $(25,0)$ dan $(75,1) € \mu(\mathrm{z})=0.03(\mathrm{z}-25)$

$\mu(\mathrm{z})=1 € \mathrm{z}=0.7 / 0.03+25=48$

Persamaan garis OFF melalui $(25,1)$ dan $(75,0) € \mu(z)=-0.03(z-75)$

$\mu(\mathrm{z})=0.3 € \mathrm{z}=0.3 /(-0.03)+75=65$

Defuzzifikasi $Z^{*}=\frac{(1 \times 48)+(0.3 \times 65)}{0.3+0.7}=67.5=$ Maka kondisi dc "ON"

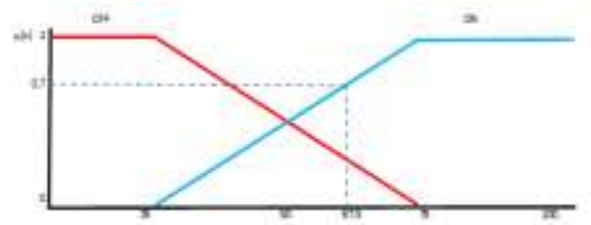

Gambar 4. Kondisi Motor Dc (output)

\subsection{Perancangan Skema Rangkaian}

Adapun dalam perancangan perangkat keras maka dibutuhkan skema jalur dari setiap alat yang digunakan, agar mempermudah memahami cara kerja dari alat tersebut, adapun perancangan skema jalsssssssur rangkaian yang akan dibuat adalah sebagai berikut :

1. Sensor Air Hujan sebagai input terhadap mikrokontroler arduino uno :

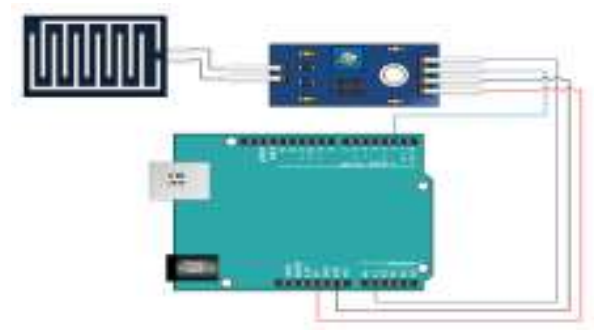

Gambar 5. Skema Jalur Sensor Air Hujan

2. Sensor LDR sebagai input :

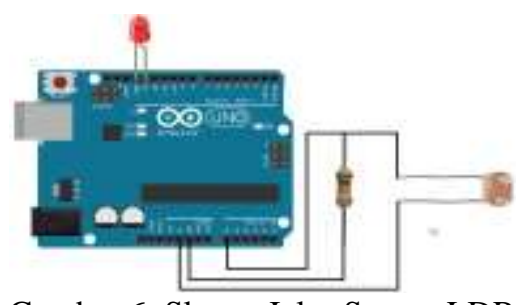

Gambar 6. Skema Jalur Sensor LDR 
MEDIA INFORMATIKA BUDIDARMA, Vol 2, No 1, Januari 2018

ISSN 2614-5278 (media cetak)

ISSN 2548-8368 (media online)

Hal $15-25$

3. Motor Dc sebagai output dari sensor Air Hujan dan LDR :

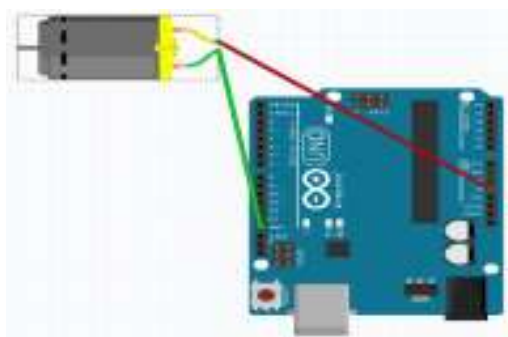

Gambar 7. Skema Jalur Sensor Motor Dc

4. Skema kerja mikrokontroler terhadap prototype yang akan di buat :

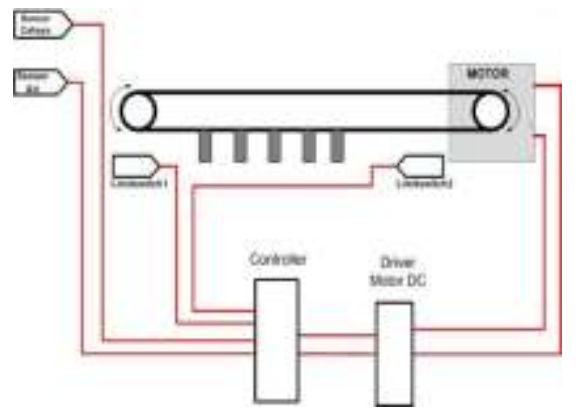

Gambar 8. Skema Jalur Jemuran Otomatis

Dari hasil skema diatas maka di rancang sebuah penempatan pada perangkat keras yang berupa sensorsensor, mikrokontroler arduino uno dan motor dc pada rumah ataupun tempat dari sebuah jemuran otomatis sebagai berikut :

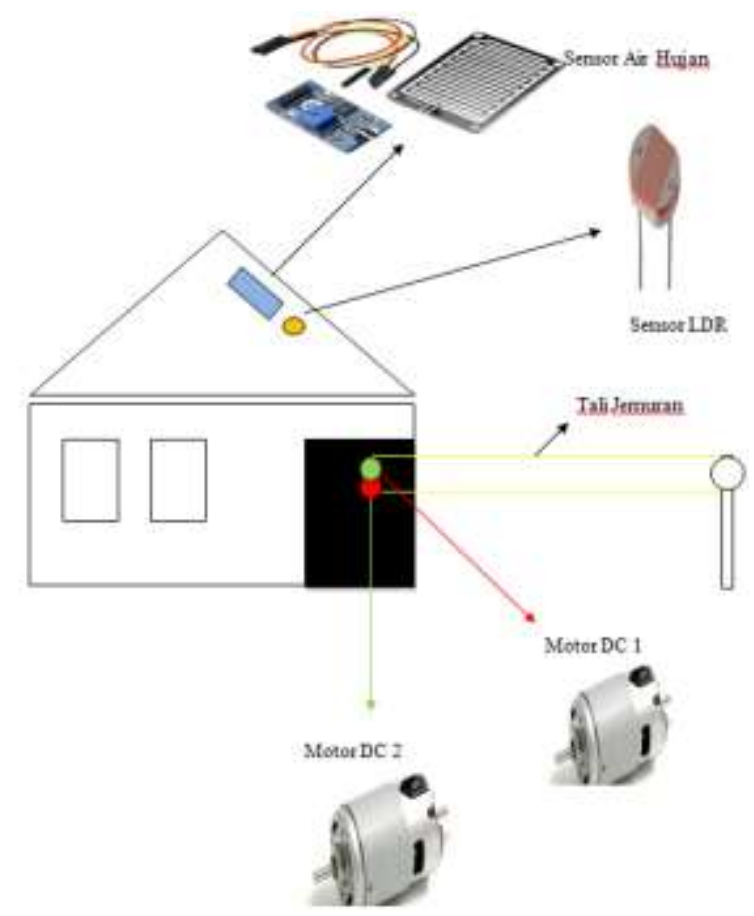

Gambar 9. Jemuran Otomatis 


\section{IMPLEMENTASI}

Implementasi adalah suatu tindakan atau pelaksanaan dari sebuah rencana yang sudah disusun secara matang dan terperinci. Implementasi biasanya dilakukan setelah perencanaan sudah dianggap selesai. Sistem yang dibuat menggunakan sebuah alat mikrokontroler arduino uno dan software arduino ide 1.8.3, yang digunakan untuk merancang sistem pada jemuran otomatis adalah sebuah software yan telah di instal pada operating sistem seperti operating sistem windows maupun linux, adapun tampilan dari software yang digunakan adalah sebagai berikut :

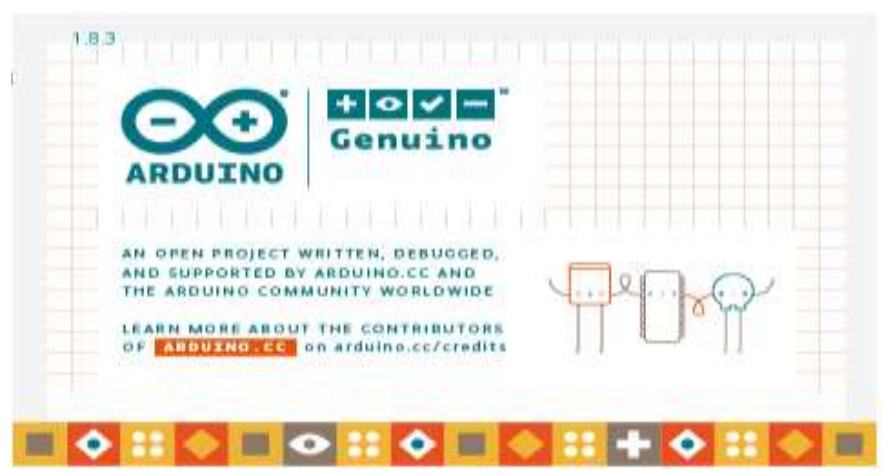

Gambar 10. Arduino IDE 1.8.3

Di atas adalah sebuah tampilan startup ketika program dijalankan, menjalankan program tersebut bisa dengan menekan double klik pada mouse tehadap icon arduino pada desktop yang berbentuk angka 8 tertidur seperti gambar tampilan di atas. Setelah program terbuka maka akan tampil di menu utama program berupa sketch atau sebuah lembar kerja untuk melakukan pemrograman terhadap mikrokontroler arduino uno, adapun tampilan menu sketch adalah sebagai berikut

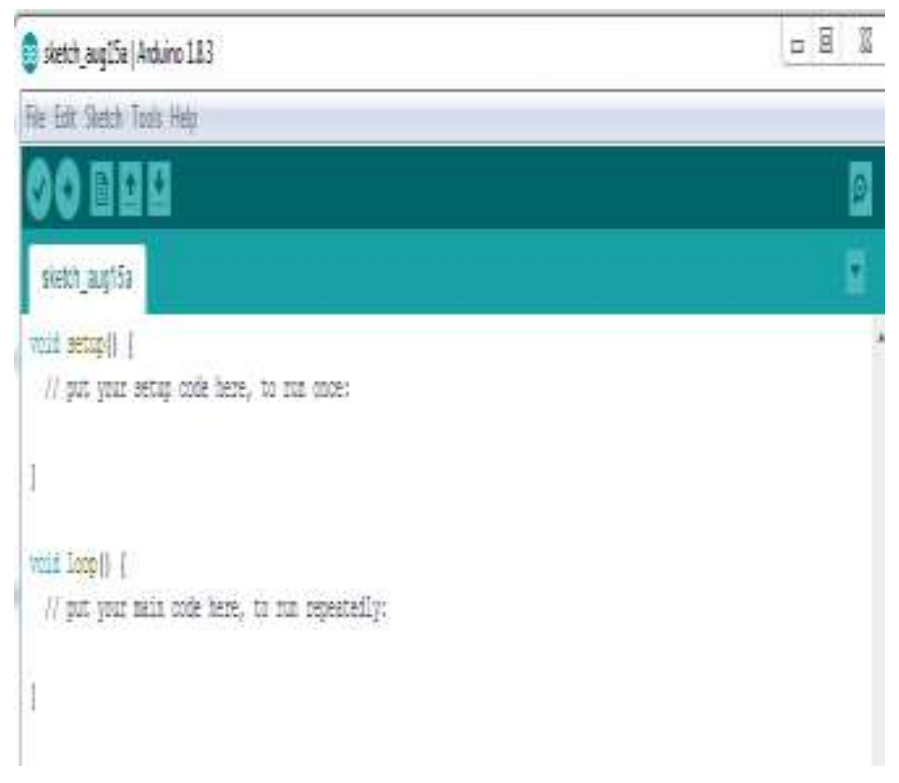

Gambar 11. Tampilan Sketch Arduino IDE 1.8.3

Di atas adalah sebuah tampilan sketch yaitu sebuah lembar kerja ketika kita akan membuat program yang akan di masukan ke dalam mikrokontroler arduino uno.

\section{Hasil Pengujian}

Adapun beberapa hasil pengujian dari pembuatan sistem yang di program menggunakan arduino ide 1.8.3 terhadap mikrokontroler arduino uno adalah sebagai berikut :

1. Sensor ldr (Light Defendant Resistor)

Pada sketch ldr digunakan sebagai input terhadap arduino uno yang disambungan dengan pin 3 pada mikrokontroler arduino uno adapun tampilan sketchnya adalah sebagai berikut : 


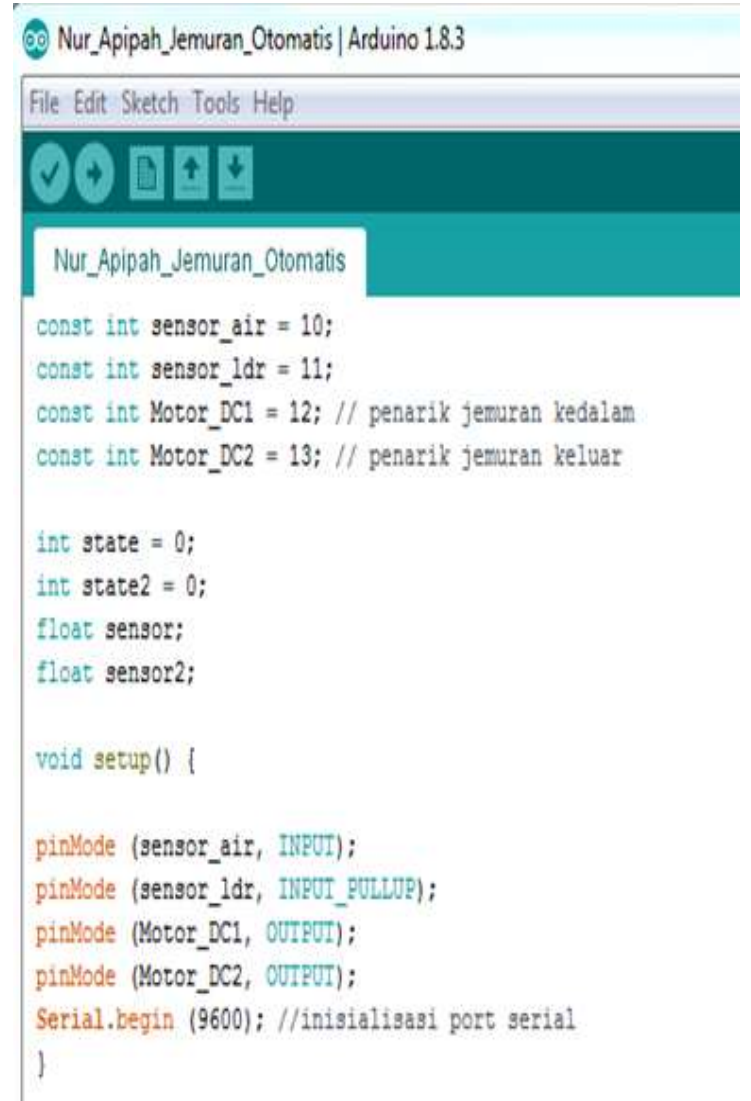

Gambar 12. Tampilan sketch sensor $l d r$

Gambar diatas adalah penempatan sensor $l d r$ pada pin 11 terhadap mikrokontroler arduino uno, serta menjadikannya sebuah input pada mikrokontroler arduino uno.

2. Sensor Air

Sensor air sama halnya dengan sensor $l d r$, sensor air merupakan sebuah input dari sistem prototype jemuran otomatis yang dihubungankan dengan mikrkontroler arduino uno, adapun tampilan sketch dari sensor air adalah sebagai berikut :

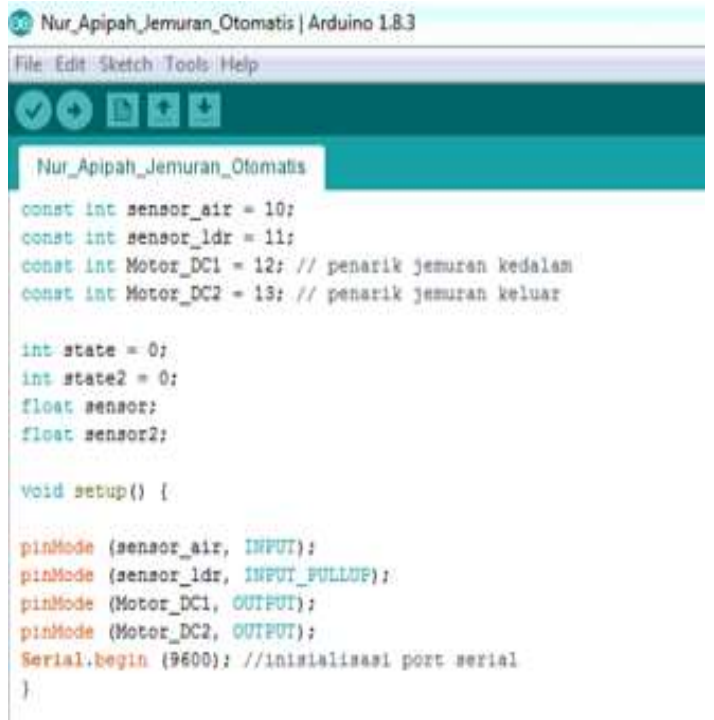

Gambar 13. Tampilan sketch sensor air 
Gambar diatas adalah tampilan sketch dari sensor air yang dimana sensor air dihubungkan pada pin 10 dan menjadi sebuah input terhadap mikrokontroler arduino uno.

3. Motor DC / Penarik Jemuran

Motor DC atau penarik jemuran adalah sebuah output dari sistem yang dibuat, dimana motor dc ini akan hidup atau menarik pakaian apabila ada input dari sensor air dan sensor ldr. Adapun tampilan sketch Motor Dc atau penarik jemuran adalah sebagai berikut :

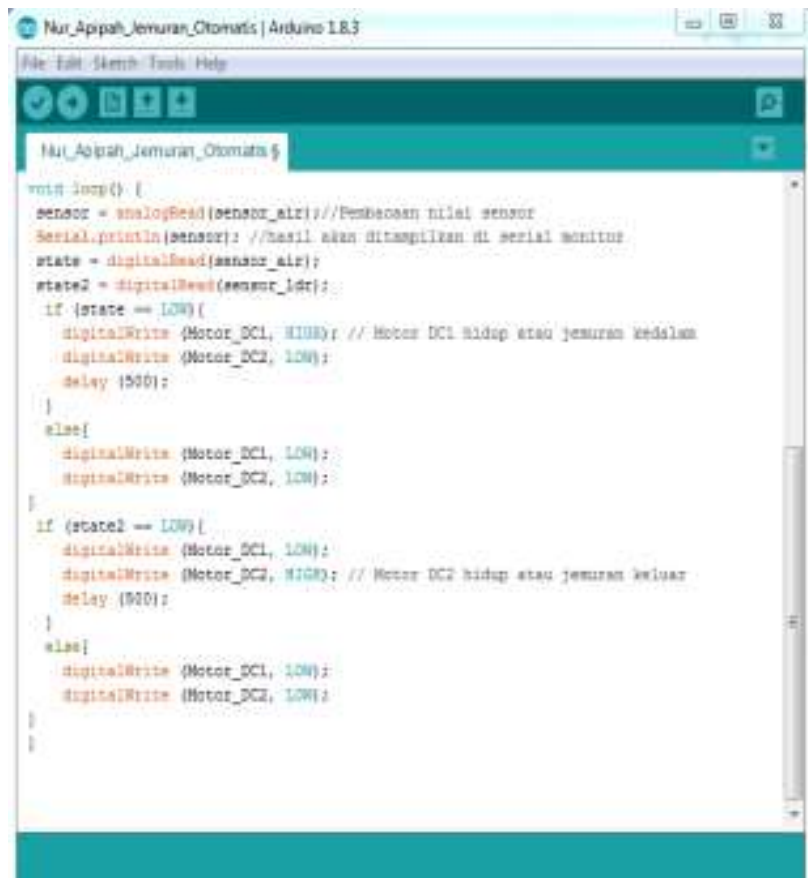

Gambar 14. Tampilan sketch Motor DC

Diatas adalah tampilan sketch motor dc, dimana motor dc di bagi menjadi 2 yaitu motor dc1 dan motor dc2, setiap motor dc mempunyai kerja berbeda dimana motor dc1 untuk menarik jemuran kedalam dan motor dc2 untuk menarik jemuran keluar. Motor dc ini akan bekerja apabila mikrokontroler arduino uno menerima input dari sensor air ataupun sensor ldr, dalam logika fuzzy logic yang diterapkan pada sistem prototype jemuran ini adalah bagaimana kondisi motor dc atau penarik jemuran pada saat panas akan tetap hujan, maka diatas dibuat kondisi atau state yang menempatkan prioritas pada kondisi input sensor air dan motordc 1 apabila sensor menerima kondisi hujan meskipun panas maka motor dc1 akan menarik jemuran itu kedalam.

Adapun tampilan dari keseluruhan sistem yang dirancang adalah sebagai berikut :

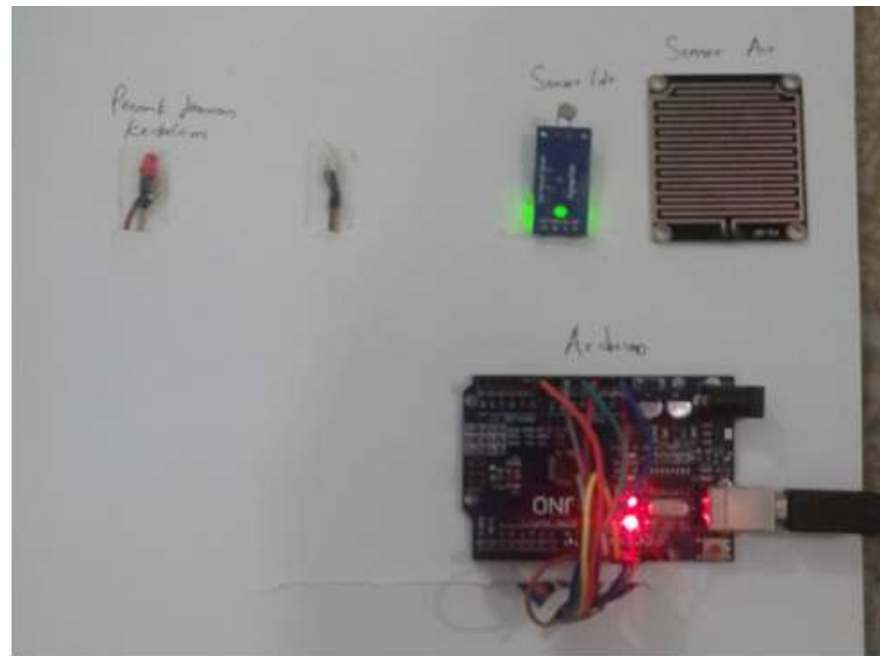

Gambar 15. Gambar Hadware Sistem Jemuran Otomatis 
Diatas adalah sistem yang berbentuk sebuah hadware yang telah dilakukan pengujian dan menghasilkan output yang sesuai dengan program yang di tanamkan terhadap mikrokontroler arduino uno. Adapun hasil pengujian terhadap sistem prototype jemuran otomatis adalah sebagai berikut

Tabel 1. Hasil Pengujian

\begin{tabular}{ccc}
\hline NO & \multicolumn{1}{c}{ KONDISI (INPUT) } & \multicolumn{1}{c}{ HASIL } \\
(OUTPUT)
\end{tabular}

Berdasarkan hasil dari tabel pengujian tabel diatas, maka didapatkan output pada sistem yang berupa hadware sebagai berikut :

1. Pengujian pada tabel kondisi 1

Disini alat diuji dimana sensor air tidak terkena basah atau tetesan air hujan, namun sensor ldr menangkap gelap atau tertutup, maka pada kondisi isi jemuran akan masuk kedalam dengan dikondisikan oleh lampu led warna merah yang menyala, sebagai tanda jemuran masuk kedalam. Adapun pengujian hasil seperti berikut :

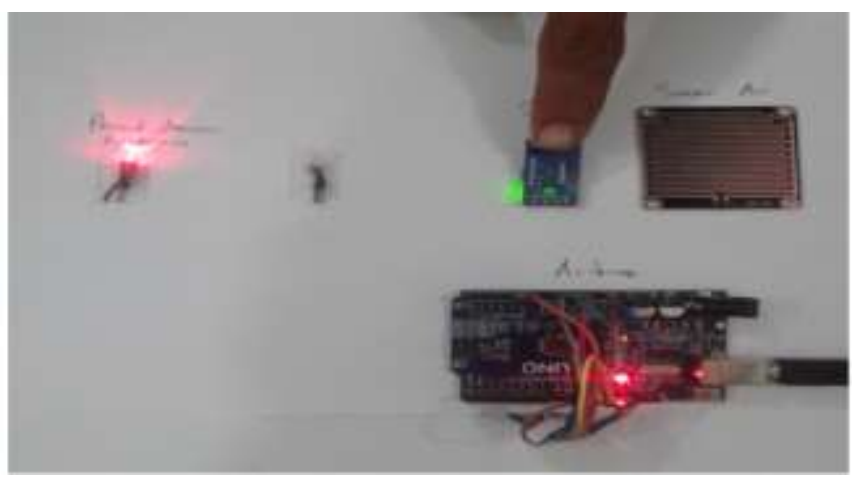

Gambar 16. Kondisi 1

2. Pengujian pada tabel kondisi 2

Pada kondisi ini dilakukan pengujian dimana sensor air tidak basah atau tidak terkena air hujan dan sensor ldrpun menangkap terang, maka jemuran otomatis akan menarik jemuran tersebut keluar, kondisi ini di kondisikan dengan lampu led berwarna biru hidup dimanan kondisi ini jemuran akan menarik keluar ketika sensor ldr menangkap terang dan sensor air hujan tidak basah atau tidak terkena air hujan, adapun hasil kondisi 2 sebagai berikut :

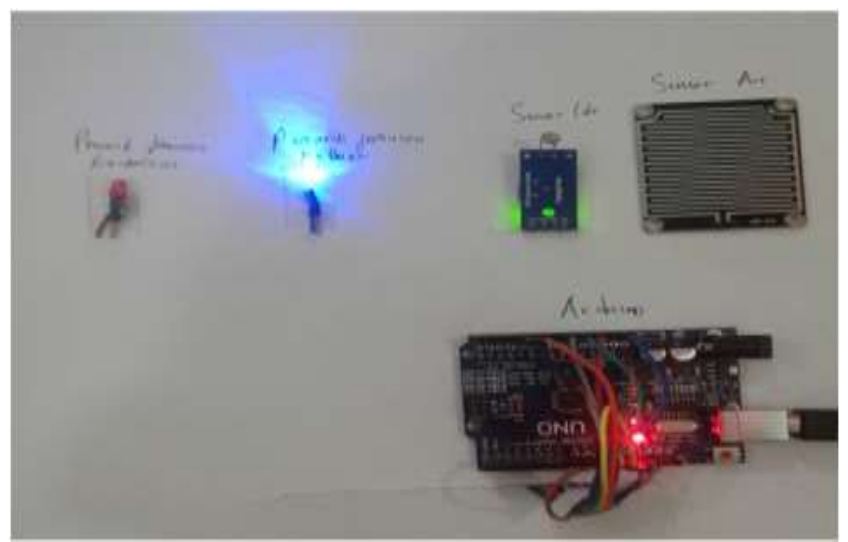

Gambar 16. Kondisi 2

Nur Apipah Harahap | http://ejurnal.stmik-budidarma.ac.id/index.php/mib | Page | 23 
3. Pengujian pada tabel kondisi 3

Pengujian kondisi 3 adalah sebuah pengujian dari latar belakang masalah yaitu ketidak samar-samar kondisi cuaca dimana terang akan tetapi hujan, maka kondisi ini di uji dengan sensor ldr menangkap terang dan sensor air menangkap basah atau tetesan air hujan, maka hasil uji ini jemuran akan masuk kedalam dapat dilihat seperti gambar di bawah yang di kondisikan dengan lampu led merah yang menyala dimana penarik menarik jemurannya kedalam, seperti berikut :

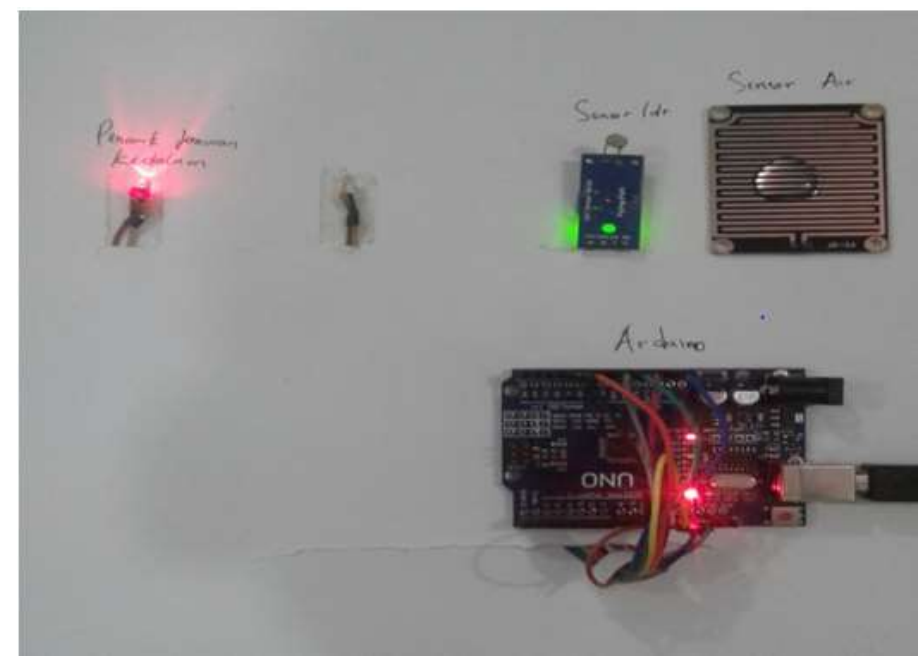

Gambar 17. Kondisi 3

Dari hasil pengujian sistem diatas maka dapat disimpulkan, bahwa sistem yang dibuat terhadap mikrokontroler arduino uno dengan memecahkan suatu masalah dimana kondisi 3, yaitu kondisi disaat cuaca sedang panas atau terang akan tetapi terjadi hujan tanpa mendung atau gelap terlebih dahulu, maka sistem jemuran otomatis ini akan menarik jemuran kedalam, yang bertujuan untuk menimalisir pakaian yang sedang dijemur tidak semuanya basah, kondisi inipun di jelaskan pada gambar kondisi 3 diatas dimana sensor ldr menangkap terang akan tetapi sensor air menangkap basah atau tetesan air hujan, maka seketika arduino memerintahkan penarik jemuran untuk menariknya kedalam yang di kondisikan dengan lampu led merah yang menyala.

\section{KESIMPULAN}

Berdasarkan data hasil pengujian jemuran otomatis menggunakan mikrokontroller arduino uno, dapat di ambil beberapa kesimpulan berikut :

1. Proses jemuran saat ini banyak ditemukan dengan cara manual dimana pakaian di masukan dan di keluarkan dengan cara menggunakan tangan seseorang. Hal ini yang menjadi sebuah masalah apabila seseorang tidak berada di rumah namun jemuran berada di luar dan hujan tiba-tiba datang. Maka perancangan jemuran otomatis ini adalah salah satu solusi menjawab masalah tersebut dimana jemuran akan menarik dengan sendirinya pakaian apabila cuaca gelap, hujan, maupun cuaca panas namun tiba-tiba hujan, maka jemuran otomatis ini akan segera menarik pakaian ke dalam rumah atau tempat yang terlindung dari air hujan.

2. Proses ketidak pastian seperti halnya panas akan tetapi hujan inilah yang menjadi sebuah permasalahan, oleh sebab itu digunakan sebuah logika fuzzy pada penerapan sistem yang di proses oleh mikrokontroler arduino uno terhadap kondisi motor dc. Dimana mikrokontroler arduino tersebut mengontrol motor dc atau penarik jemuran kapan saat pakaian di tarik kedalam dan kapan saat pakaian di tarik keluar.

3. Pada tahap pengujian, sistem yang di terapkan pada mikrokontroler arduino uno berjalan sesuai dengan proses logika fuzzy yang telah di tentukan berdasarkan latar belakang masalah penyusunan skripsi, dimana jemuran akan menarik pakaian kedalam apabila kondisi panas namun terjadi hujan.

\section{REFERENCES}

[1] Ebta setiawan. (2016, January) Kamus Besar Bahasa Indonesia. [Online]. http://kbbi.web.id/rancang

[2] Simarmata Janner, Rekayasa Perangkat Lunak. Yogyakarta, Indonesia: ANDI OFFSET, 2010.

[3] Ebta Setiawan. (2016, January) Kamus Besar Bahasa Indonesia. [Online]. http://kbbi.we.id/jemuran 
MEDIA INFORMATIKA BUDIDARMA, Vol 2, No 1, Januari 2018

ISSN 2614-5278 (media cetak)

ISSN 2548-8368 (media online)

Hal $15-25$

[4] Ebta Setiawan. (2016, January) Kamus Besar Bahasa Indonesia. [Online]. http://kbbi.web.id/otomatis

[5] Heri Andrianto, ARDUINO BELAJAR CEPAT DAN PEMROGRAMAN. Bandung, Indonesia: ,. Bandung, Indonesia: Informatika Bandung, 2016.

[6] Dwi Ana Ratna Wati, Sistem Kendali Cerdas. Yogyakarta, Indonesia: Graha Ilmu, 2011.

[7] Solusi Rekaya Elekronika. (2017, June) Solusi Rekaya Elekronika. [Online]. http://www.vcc2gnd.com/sku/MDWTRDRS

[8] B. Sasikala S. Pooranchandra, Introduction to Electrical, Electronics and Communication Engineering. New Delhi, India: Laxmi Publications (P) LTD, 2005.

[9] M.kom Drs. Lamhot Sitorus, Algoritma dan Pemrograman. Yogyakarta, Indonesia: CV. ANDI OFFSET, 2015. 